\title{
SURFACE MODIFICATION PROCESSES ON EUROPEAN UNION BRONZE REFERENCE MATERIALS FOR ANALYTICAL STUDIES OF CULTURAL ARTEFACTS
}

\author{
T. Beldjoudi, F. Bardet, N. Lacoudre, S. Andrieu, A. Adriaens, I. Constantinides, \\ and P. Brunella
}

This paper presents research results obtained in the 4th Framework Programme (1994-1998) of the Standards, Measurements, and Testing Programme of the European Union, DG XII: 'Improvement of means of measurements on archaeological copper alloys for characterisation and conservation' (IMMACO) project. One of the aims of this project was to study copper alloy compositions of European objects dating from the Bronze Age to Roman times. This work has revealed that five types of alloy seem to be particularly representative of what was produced in Europe during this period. These alloy compositions will be certified as reference materials by the European Union. In the second part, artificial patinas have been made on the different bronze alloys using electrochemical polarisation as the surface modification technique. The characterisation of the corrosion surfaces and interfaces formed during the treatment with light microscopy and scanning electron microscopy (SEM-EDX, X-ray mapping) have shown that the artificial patinas seem

\section{INTRODUCTION}

The European IMMACO (Improvement of means of measurements on archaeological copper alloys for characterisation and conservation) programme fits into the general framework of protecting and preserving the European Union's artistic and archaeological heritage. Its initial objectives were to create standard samples of copper alloys with compositions representative of the archaeological artefacts in order to optimise the calibration of instruments for analysing composition (XRF). In the second phase, the purpose of the research was to perfect a simple experimental protocol for the formation of artificial patinas similar to those generally observed on buried archaeological artefacts. This was done using an electrochemical method to synthesise specimens.

In the first phase of the work, a statistical study was performed in which 3600 analyses of archaeological artefacts found in the scientific literature were examined. A set of five compositions of copper alloys was defined, which were representative of the compositions of archaeological artefacts dating from different periods. ${ }^{1}$ In the second phase of the work, it was demonstrated that a simple and repeatable 'generic' electrochemical procedure can be used to create artificial patinas similar in composition and structure to those on archaeological artefacts. The surfaces formed were analysed by the various partners in the European programme and were compared to real patinas on objects from the archaeological site at Bliesbrück-Reinheim (Moselle), France. to be very close to those from excavations. As a consequence the patinated specimens can be used as a substitute for genuine artefacts in the future to improve conservation techniques.

SE/S193

Dr Beldjoudi is with Step S.A., 3 Place des Pianos, 93200 Saint-Denis, France, Ms Bardet and Mr Lacoudre are with EDF, Groupe des Laboratoires, Laboratoire Valectra, 2 rue Ampère, 93206 SaintDenis, Cedex 1, France, Dr Andrieu is at ENSAM, LM3, 151 Boulevard de l'Hôpital, 75013 Paris, France, Dr Adriaens and Ms Constantinides are at the University of Antwerp, Department of Chemistry, Universiteitsplein 1, B-2610 Wilrijk, Belgium, and Dr Brunella is at the Stiftung Europaïsche Kulturpark, Bliesbrück-Reinheim, F-57200 Bliesbrück, France. Contribution to the 14th International Conference on Surface Modification Technologies held in Paris on 11-13 September 2000.

(C) 2001 IoM Communications Ltd.

\section{CHOICE OF IMMACO ALLOYS}

The compositions of the copper alloys synthesised within the context of the programme were decided following a statistical study, which was carried out at the EDF's Valectra laboratory. For this 3600 elemental analyses of archaeological artefacts were taken from the scientific literature. ${ }^{1}$ This bibliographical study was based on three main criteria: the countries, the periods, and the types of copper alloys. As a result of the analysis, five compositions of copper alloys were defined as representative of the archaeological artefacts found in four European countries (France, Germany, Greece, and Italy) dating from the Bronze Age to the Roman period.

The results of analyses collected for France make up the largest body of artefacts: 503 objects from the Bronze Age, 224 objects from the Iron Age, and 590 objects from the Roman Period. From these results, the average elemental composition for each of the alloys was calculated and weighted by the number of objects. These variations in composition are shown in Fig. 1.

However, when analysing the diagram in Fig. 1, the greatest prudence should be exercised before drawing conclusions concerning the relative importance of certain alloys in relation to others. There are two reasons for this. First, the number of objects presented depends on the bibliographical sources found. Thus, the fact that there are few examples of a given type of alloy does not mean that this alloy was not made at the period concerned, but rather 

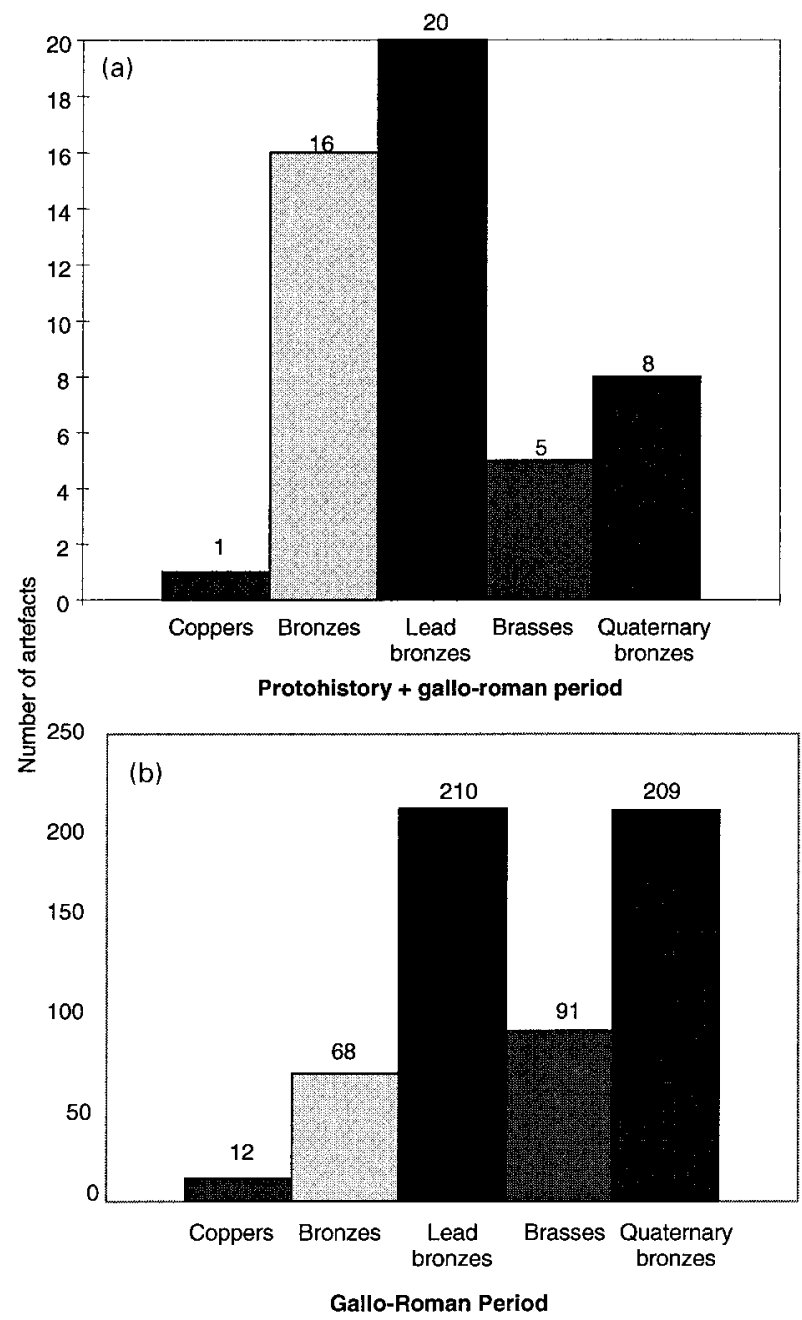

1 Frequency of types of $\mathrm{Cu}$ alloys in a Bliesbrück-Reinheim and $\boldsymbol{b}$ French corpus

that not many bibliographical sources were found concerning that alloy. A good example of this is the Iron Age; few objects dating from this period have been analysed, not because the Iron Age founders only made a few objects in bronze, but because researchers have been more interested in analysing Bronze Age and Roman period bronzes and have not shown much interest in Iron Age bronzes. Second, the number of objects made of a type of alloy also depends on the type of object made. Thus in studying the Gallo-Roman part of the histogram, first instincts say: the founders mainly made lead bronzes and quaternary $\mathrm{Cu}-\mathrm{Sn}-\mathrm{Pb}-\mathrm{Zn}$ alloys. However, looking at the type of objects made, it can be seen that they are mainly cast figurines, for which the purity of the type of alloy is not very important. It could even be said that the addition of lead is essential because this element liquefies the pouring.

Bearing these two factors in mind, the study of the histogram corresponding to the French corpus (Fig. 1b) shows the following. As the date increases a diversification of the types of alloys can be seen. Thus in the Bronze Age, a change can be observed from unalloyed copper to tin bronze, and then to lead bronze. Then, at the end of the Iron Age, the brasses and quaternary alloys appear (the making of brass was probably mastered by direct reduction of calamine in the presence, whether deliberate or accidental, of copper ore). Finally, starting from the Gallo-

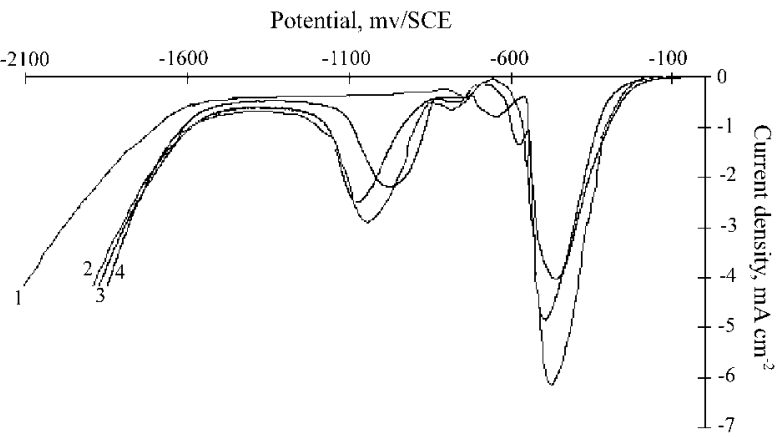

1: oxidation in $0 \cdot 1 \mathrm{M} \mathrm{Na} \mathrm{SO}_{4} ; 2$ : oxidation in $0 \cdot 01 \mathrm{M}$ $\mathrm{Na}_{2} \mathrm{SO}_{4}+2 \cdot 82 \times 10^{-2} \mathrm{M} \mathrm{NaCl} ; 3$ : oxidation in $2.82 \times 10^{-2} \mathrm{M}$ $\mathrm{NaCl}$; 4: oxidation in ASTM solution $\left(\mathrm{NaCl}, \mathrm{Na}_{2} \mathrm{SO}_{4}\right.$, and $\mathrm{NaHCO}_{3}$ )

2 Electrochemical analysis of corrosion products formed on quaternary bronze in given electrolytes

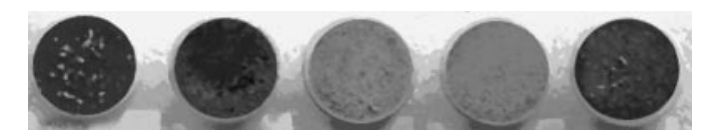

3 Artificial patinas formed on specimens of five IMMACO alloy compositions by electrochemical means: specimens (from left to right) are quaternary bronze, arsenic copper, tin bronze, lead bronze, and brass

Roman Period onwards, the five types of alloy coexisted. Therefore, it seems that Gallic metallurgical production from the Bronze Age to the Gallo-Roman period can be described in terms of five types of alloys: unalloyed copper, tin bronze, lead bronze, brass, and the quaternary alloy.

This procedure was also applied to artefacts from the other countries used in this study. Thus, the five compositions of alloys were determined corresponding to an arsenical copper, a tin bronze, a lead bronze, a quaternary bronze, and a brass, the compositions of which are given in Table 1.

The proposed compositions were confirmed by analyses carried out on archaeological artefacts from the site at Bliesbrück-Reinheim. Some of the same types of alloys (copper, bronze, lead bronze, brass, and quaternary alloy) were found as those found for the general French corpus (Fig. 1). In addition, for analytical (dosage of minor elements and matrix effect problems) and archaeological (existence of alloys with a very high lead or tin content) reasons, five other uncertified compositions were determined. These five alloys, however, do not fit within the scope of this article.

The specimens were synthesised by the Institute for Reference Materials and Measurements in Geel, Belgium (cold isostatic pressing, 1500 bar, before encapsulation in stainless steel for hot isostatic pressing, $820^{\circ} \mathrm{C}, 1000 \mathrm{bar}$, under argon gas). The specimens were then used for the second phase of the present work: to develop an electrochemical procedure for the formation of surface patinas.

\section{FORMATION OF ARTIFICIAL PATINAS}

The aim of the second phase of the present work was to create corroded surfaces on the copper alloy specimens defined above, similar to those found on buried archaeological artefacts. The research mainly focused on the formation and analysis of the corrosion products of copper alloys by electrochemical means. 


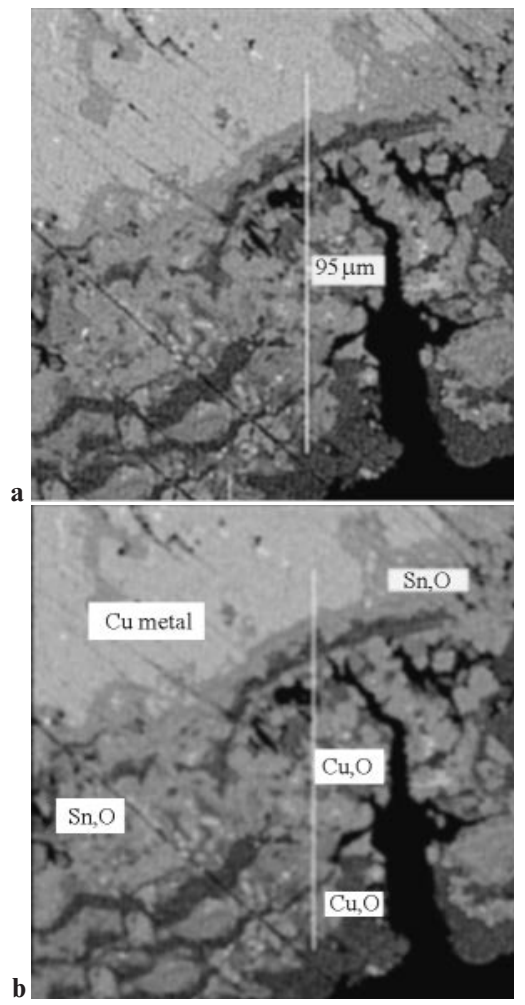

4 a SEM cross-sectional image of binary bronze after electrochemical treatment and $\boldsymbol{b} X$-ray mapping of alloy using electron probe microanalyser

$\times 300$

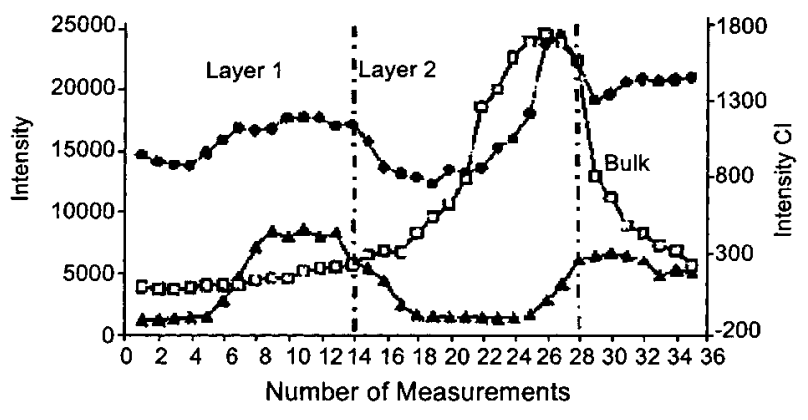

- $\mathrm{Cu} 29 ; \boldsymbol{\Delta} \mathrm{Sn} 50 ; \square 12 \mathrm{Cl} 17$

5 Line scan profiles of $\mathrm{Cu}, \mathrm{Sn}$, and Cl across cross-section on binary alloy: accelerating voltage $20 \mathrm{kV}$, line $75 \mu \mathrm{m}$, counting time $50 \mathrm{~s}$

First, earlier work carried out at the Valectra laboratory (see Ref. 2) was reviewed in order to better direct the experiments with the aim to perfect the procedure for the selective formation of corrosion products.

The first experiments were carried out on the basis of a slightly alloyed copper and a quaternary bronze ( $\mathrm{Sn}, \mathrm{Pb}$, and $\mathrm{Zn}$ ). Thus, using several types of monoanionic, bianionic, and trianionic $\left(\mathrm{Na}_{2} \mathrm{SO}_{4}\right.$, $\mathrm{NaCl}$, and $\mathrm{NaHCO}_{3}$ ) electrolytes, the nature of the surface compounds was shown, which could be
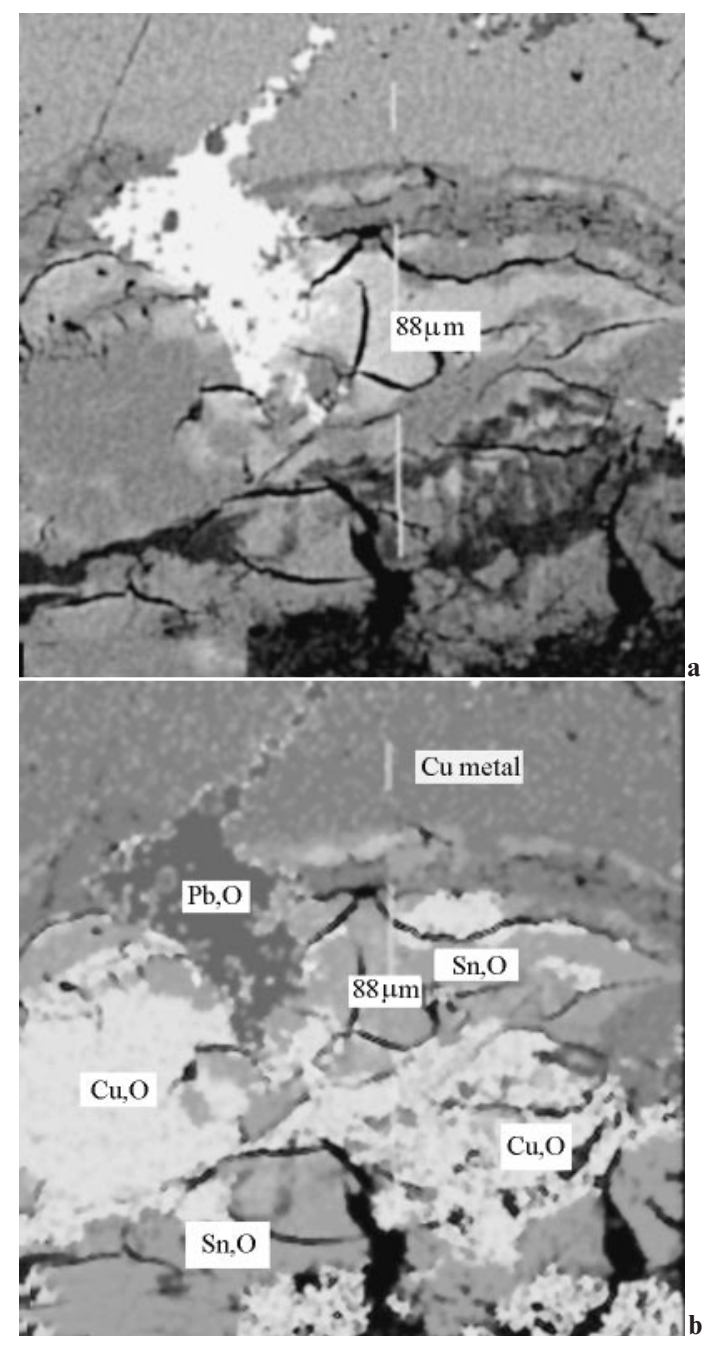

6 a SEM cross-sectional image of quaternary bronze after electrochemical treatment and $\boldsymbol{b} X$-ray mapping of alloy using electron probe microanalyser

$\times 600$

synthesised and analysed by electrochemical means (Fig. 2). In the same way, many tests were carried out to select the electrolytes and determine the oxidation potentials required for selectively forming the various copper compounds, in particular cuprite. ${ }^{3}$

Thus, an experimental protocol was drawn up and applied to the five compositions of alloys defined above. This procedure was divided into two stages: the first corresponded to the selective formation of cuprite $\left(\mathrm{Cu}_{2} \mathrm{O}\right)$ on the specimens in a solution of sodium sulphate $\left(\mathrm{Na}_{2} \mathrm{SO}_{4}\right)$, with a concentration of $0 \cdot 1 \mathrm{M}$ and an anodic potential of $40 \mathrm{mV} / \mathrm{SCE}$. The second stage allows for the formation of more 'complex' compounds including chlorides, carbonates, and sulphates in an ASTM solution with added carbonates $\left(0 \cdot 01 \mathrm{M} \mathrm{Na} \mathrm{Na}_{2} \mathrm{SO}_{4}, 2 \cdot 82 \times 10^{-2} \mathrm{M} \mathrm{NaCl}\right.$, $16 \cdot 1 \times 10^{-2} \mathrm{M} \mathrm{NaHCO} 3$ ). The total duration of the electrochemical treatment is less than 1 month. The

Table 1 Composition of five representative $\mathrm{Cu}$ alloys found in archaeological artefacts, wt- $\%$

\begin{tabular}{|c|c|c|c|c|c|c|c|c|c|c|}
\hline $\mathrm{Cu}$ alloy & $\mathrm{Sn}$ & $\mathrm{Pb}$ & As & $\mathrm{Zn}$ & $\mathrm{Fe}$ & $\mathrm{Mn}$ & $\mathrm{Ni}$ & $\mathrm{S}$ & $\mathrm{Sb}$ & $\mathrm{Cu}$ \\
\hline Quaternary bronze & $7 \cdot 00$ & $9 \cdot 00$ & $0 \cdot 20$ & $6 \cdot 00$ & $02 \cdot 0$ & $0 \cdot 20$ & $0 \cdot 10$ & $0 \cdot 30$ & $0 \cdot 50$ & Bal. \\
\hline Arsenic copper & $0 \cdot 20$ & $0 \cdot 20$ & $5 \cdot 00$ & $\ldots$ & $0 \cdot 20$ & $0 \cdot 20$ & $\ldots$ & $0 \cdot 30$ & $0 \cdot 50$ & Bal. \\
\hline Tin bronze & $7 \cdot 00$ & $0 \cdot 20$ & $0 \cdot 20$ & $0 \cdot 10$ & $0 \cdot 30$ & $0 \cdot 30$ & $0 \cdot 50$ & $0 \cdot 50$ & $0 \cdot 70$ & Bal. \\
\hline Lead bronze & $10 \cdot 00$ & $10 \cdot 00$ & $0 \cdot 30$ & $0 \cdot 10$ & $0 \cdot 10$ & $0 \cdot 10$ & $0 \cdot 30$ & $\ldots$ & $0 \cdot 30$ & Bal. \\
\hline Brass & $2 \cdot 00$ & $0 \cdot 40$ & $0 \cdot 10$ & $15 \cdot 00$ & $0 \cdot 50$ & $0 \cdot 40$ & $0 \cdot 20$ & $0 \cdot 30$ & $\ldots$ & Bal. \\
\hline
\end{tabular}



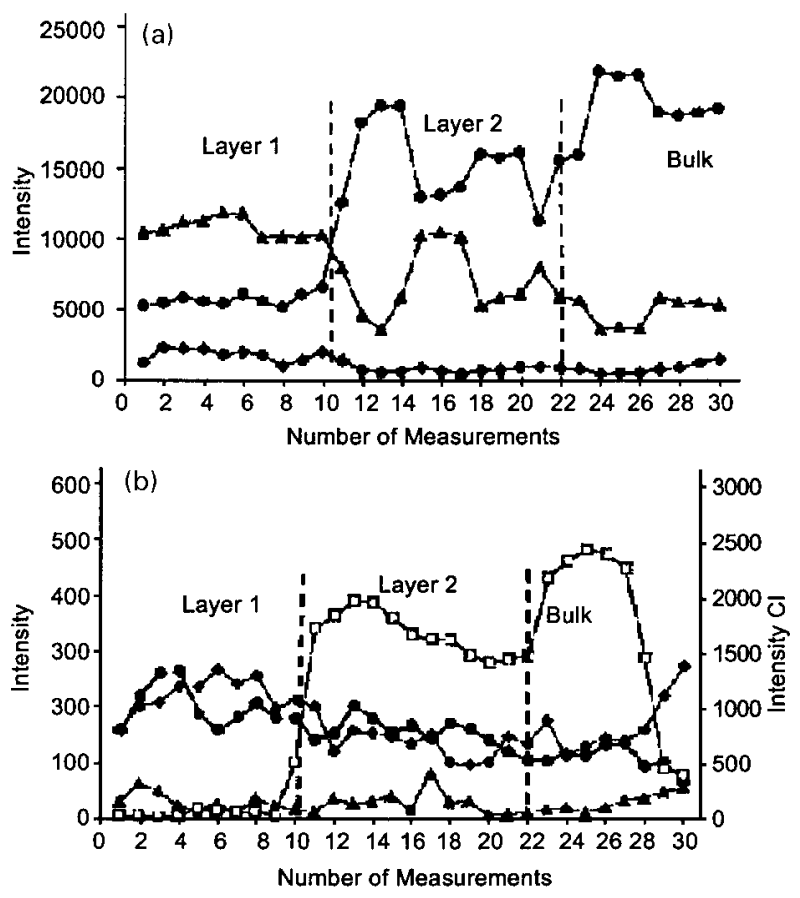

$a \bullet \mathrm{Cu} 29, \boldsymbol{\Delta} \mathrm{Sn} 50, \diamond \mathrm{Zn} \mathrm{30;b} \bullet \mathrm{Fe} 26, \boldsymbol{\Delta} \mathrm{Mn} 25, \diamond \mathrm{Si}$ $14, \square \mathrm{Cl} 17$

7 Line scan profiles of $\boldsymbol{a} \mathrm{Cu}, \mathrm{Sn}$, and $\mathrm{Zn}$ and $\boldsymbol{b} \mathrm{Si}, \mathrm{Mn}, \mathrm{Fe}$, and $\mathrm{Cl}$ across cross-section of patina on quaternary alloy: accelerating voltage $20 \mathrm{kV}$, line $30 \mu \mathrm{m}$, counting time $50 \mathrm{~s}$

surface patinas obtained using this experimental protocol were observed and analysed to determine the nature of the surface compounds and interfaces formed (Fig. 3).

\section{ANALYSIS AND COMPARISON OF ARTIFICIAL PATINAS}

First, the surface products were analysed, using X-ray diffraction (XRD) and X-ray fluorescence (XRF) spectrometry to identify the elements present in the specimen and the crystallised compounds. Next, the corrosion structures were observed by studying crosssections under an SEM to determine the stratigraphy of the surface layers. Maps were made of the elementary compounds, using an X-ray electron probe microanalyser, and line scans were carried out to trace the concentrations of selected elements.

The results of the surface analyses obtained using XRD and XRF showed the presence of cuprite $\mathrm{Cu}_{2} \mathrm{O}$ on all the specimens, and the presence of malachite $\mathrm{Cu}_{2}\left(\mathrm{CO}_{3}\right)(\mathrm{OH})_{2}$, cerrusite $\mathrm{PbCO}_{3}$, and cassiterite $\mathrm{SnO}_{2}$ on certain alloys. All these products of corrosion are frequently found on archaeological artefacts. The results of the X-ray analyses obtained from the crosssections of the specimens showed, in the cases of binary bronze (Figs. 4 and 5) and quaternary bronze (Figs. 6 and 7) for example, an enrichment in tin compounds in the surface layers and particularly on the metal/corrosion product interface. ${ }^{4}$ The presence of lead oxide nodules was also observed in the case of quaternary bronze. On the whole, the corrosion structures observed on these two specimens are of the two layer type, from the metal to the corrosion products, with a layer of tin oxide covered by a layer of copper oxide. ${ }^{5}$

The corrosion structures of the specimens on which artificial patinas had been formed were compared
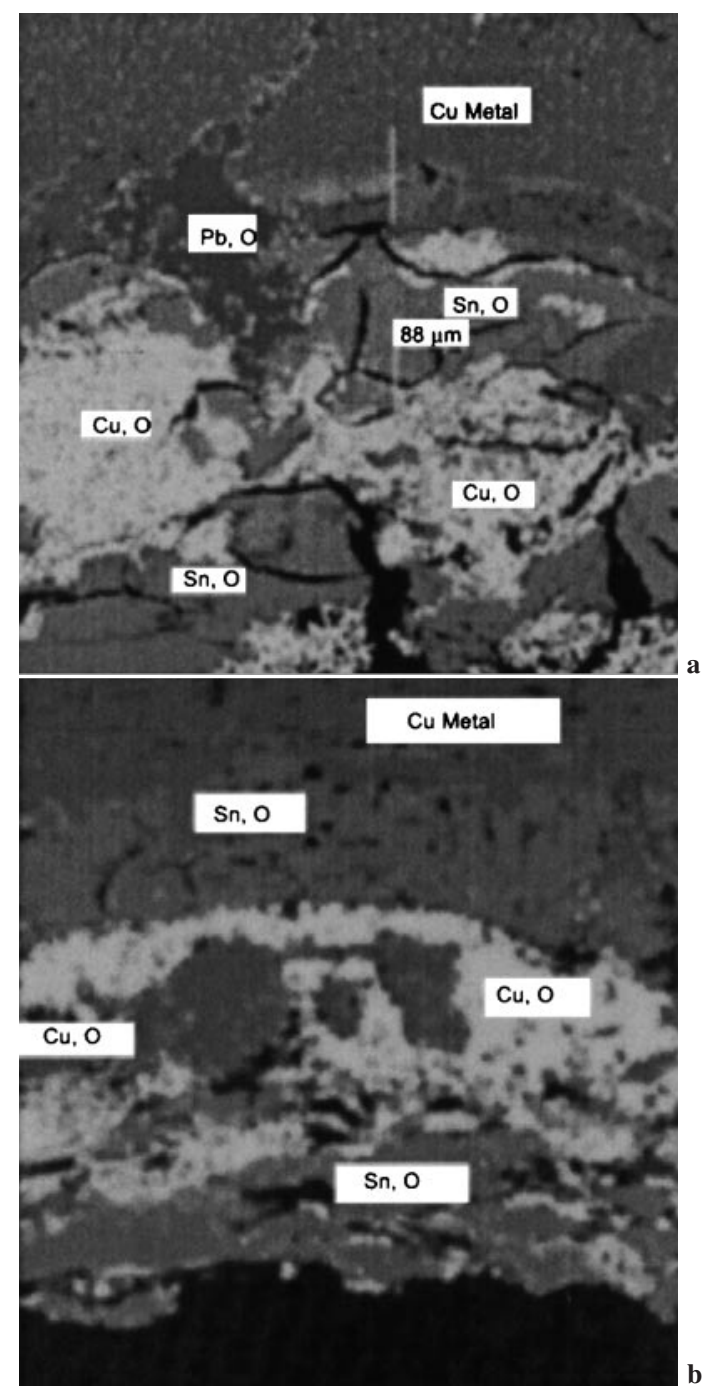

8 Comparison of corrosion structures on a artificially patinated quaternary bronze and $\boldsymbol{b}$ fragment of archaeological bronze from site at Bliesbrück-Reinheim

$\times 600$

with those observed on archaeological specimens taken from the body of objects from the site at Bliesbrück-Reinheim. In the case of quaternary bronze, there is quite a good similarity between the artificial corrosion structure and that observed on a fragment of archaeological bronze (Fig. 8).

\section{CONCLUSION}

The research carried out in the present study first statistically identified five compositions of copper alloys representative of objects dating from the Bronze Age to the Roman Period in Europe. They are an arsenical copper, a tin bronze, a lead bronze, a quaternary bronze, and a brass. These compositions of alloys will be certified by the European Union as standard samples for calibration of XRF analyses.

The artificial patinas, close in composition and structure to those observed on archaeological artefacts, were created using an experimental electrochemical procedure in an aqueous environment. The results obtained were satisfactory and on the whole satisfy the objectives set for the European IMMACO programme. It is now possible to synthesise in a simple and repeatable way the effects of corrosion on metallic specimens (certified by the European Union) 
similar to archaeological artefacts. These 'prepatinated' specimens will partially meet the requirements for optimising the present techniques for conserving and preserving our metallic cultural heritage.

\section{REFERENCES}

1. S. ANDRIEU, T. BELDJOUdI, and N. LACOUDRE: Rapport Work Package 1, EDF No. RX971602/indice 3, Saint-Denis, France, 1997.
2. T. BELDJOUDI: Rapport Tech. STEP/EDF, 'Synthèse des Travaux' Valectra, 1999.

3. T. BELDJOUDI, F. BARDET, and N. LACOUDRE: Rapport Final EDF, Work Package 3, Saint-Denis, France, 2000.

4. I. CONSTANTINIDES, A. ADRIAENS, and F. C. ADAMS: Report Work Package 6, 'Characterisation of surface layers and interfaces', IMMACO Project, 2000.

5. Bocking, P. BRUNella, FiaUd et al.: Proc. Int. Conf. on Metals Conservation (METAL 98), Draguignan, France, 1998, 145-151; 1998, London, James and James.

\section{MICROSCOPY OF OXIDATION 3}

Edited by

S.B. Newcombe and J.A. Little

Sections on

Alumina-Forming Fe Based Alloys: (a) Growth mechanisms of alumina scales, (b) The effects of sulphur and reactive element additions; ODS Alloys; Iron, Nickel and Titanium Aluminides; Coatings and Failure Modes; Aluminium, Titanium, Copper, Zirconium and Niobium; Iron, Chromium and their Alloys; Degradation in Mixed Environments; Degradation of Ceramic Materials; Author Index; Subject Index

Book 675 ISBN 1861250347 Hardback

European Union $£ 150 /$ Members $£ 120$

Non-European Union $\$ 300 /$ Members $\$ 240$

p\&p European Union $£ 5.00 /$ Non-EU $\$ 10.00$ per order

Orders to: IOM Communications Ltd, Shelton House, Stoke Road, Shelton,

Stoke-on-Trent ST4 2DR Tel: +44 (0) 1782202116 Fax: +44(0) 1782202421

Email: Orders@materials.org.uk Internet: www.materials.org.uk

VAT Registration No. GB 649164611 Reg. Charity No. 1059475

N. American orders to: Ashgate Publishing Co., Old Post Road, Brookfield, VT 05036, USA

Tel: 8022763167 Fax: 8022763837 Email: info@ashgate.com

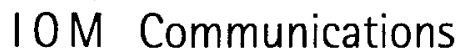

IOM Communications Ltd is a wholly-owned subsidiary of the Institute of Materials 